Florida International University FIU Digital Commons

4-4-2007

\title{
Mirror self-recognition in a gorilla (gorilla gorilla gorilla)
}

Melinda R. Allen

Florida International University

DOI: $10.25148 /$ etd.FI13101588

Follow this and additional works at: https://digitalcommons.fiu.edu/etd

Part of the Psychology Commons

\section{Recommended Citation}

Allen, Melinda R., "Mirror self-recognition in a gorilla (gorilla gorilla gorilla)" (2007). FIU Electronic Theses and Dissertations. 1066. https://digitalcommons.fiu.edu/etd/1066

This work is brought to you for free and open access by the University Graduate School at FIU Digital Commons. It has been accepted for inclusion in FIU Electronic Theses and Dissertations by an authorized administrator of FIU Digital Commons. For more information, please contact dcc@fiu.edu. 
FLORIDA INTERNATIONAL UNIVERSITY

Miami, Florida

MIRROR SELF-RECOGNITION IN A GORILLA (GORILLA GORILLA GORILLA)

A thesis submitted in partial fulfillment of the

requirements for the degree of

MASTER OF SCIENCE

in

PSYCHOLOGY

by

Melinda R. Allen

2007 
To: Interim Dean Mark Szuchman

College of Arts and Sciences

This thesis, written by Melinda R. Allen, and entitled Mirror Self-Recognition in a Gorilla (Gorilla Gorilla Gorilla), having been approved in respect to style and intellectual content, is referred to you for judgment.

We have read this thesis and recommend that it be approved.

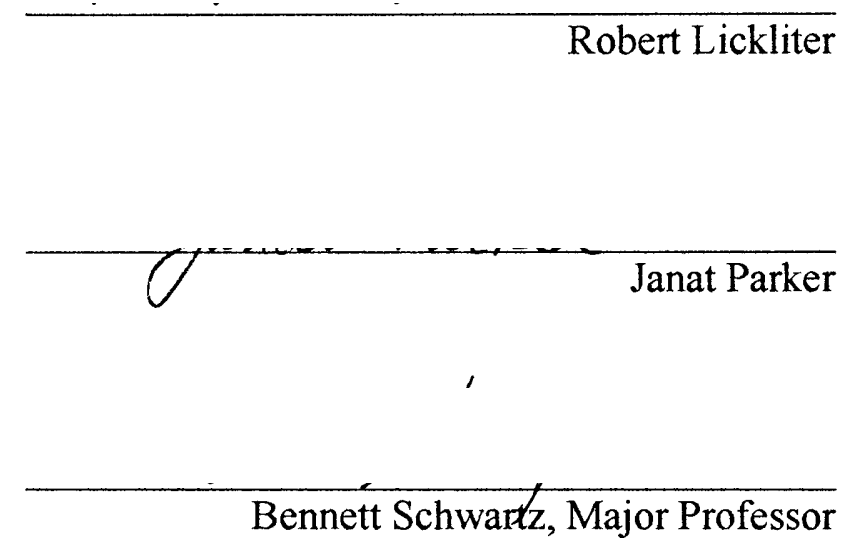

Date of Defense: April 4, 2007

The thesis of Melinda R. Allen is approved.

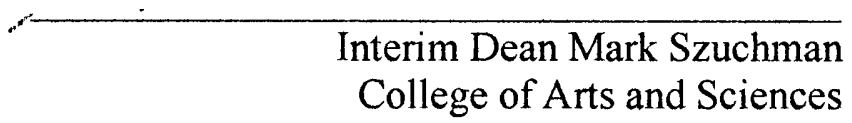

College of Arts and Sciences

Florida International University, 2007 


\begin{abstract}
OF THE THESIS
MIRROR SELF-RECOGNITION IN A GORILLA (GORILLA GORILLA GORILLA)

by
\end{abstract}

Melinda R. Allen

Florida International University, 2007

Miami, Florida

Professor Bennett Schwartz, Major Professor

Psychologists have studied self-recognition in human infants as an indication of self-knowledge (Amsterdam, 1972) and the development of abstract thought processes. Gallup (1970) modified the mark test used in human infant work to examine if nonhuman primates showed similar evidence of mirror self-recognition. Chimpanzees (Pan troglodytes) and orangutans (Pongo pygmaeus) pass the mirror self-recognition test with limited mirror training or exposure. Other species of primates, such as gorillas and monkeys, have not passed the mirror test, despite extensive mirror exposure and training (Gallup, 1979). This project examined a gorilla (G. gorilla gorilla) named Otto in the traditional mark test. Using the modified mark-test, there were more incidents of touching the marked area while Otto was in front of the mirror than when he was not in front of the mirror. These results indicated that Otto was able to show some evidence of selfawareness. 


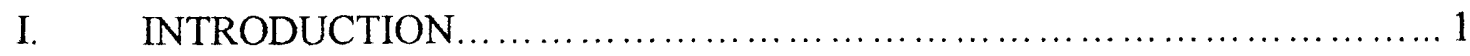

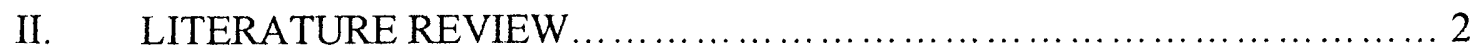

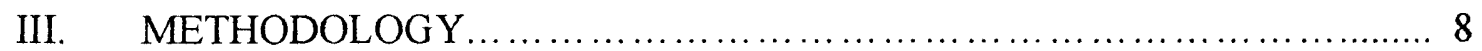

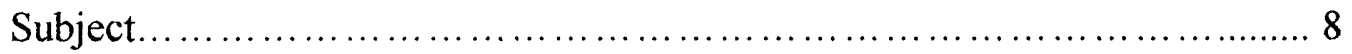

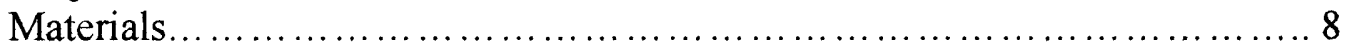

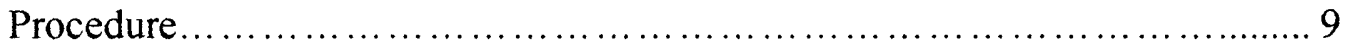

Behavioral Measurements............................................. 10

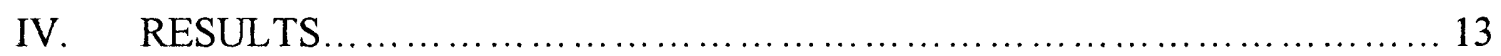

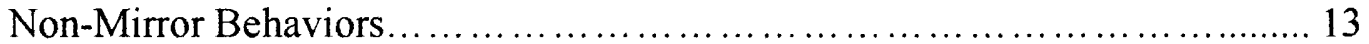

Mirror-Directed Behaviors.......................................... 14

Contingent and Mirror-Guided Behaviors ............................... 14

Mark-Directed Behaviors........................................... 14

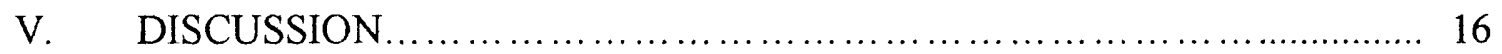

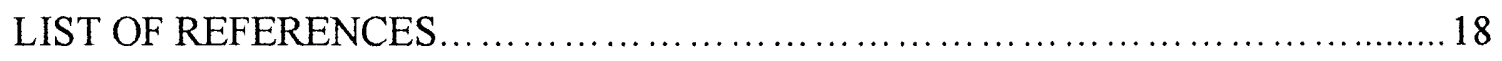

APPENDICES 


\section{CHAPTER I}

\section{INTRODUCTION}

Psychologists have studied self-recognition in human infants as an indication of self-knowledge (Amsterdam, 1972) and the development of abstract thought processes. Gallup (1970) modified the mark test used in human infant work to examine if nonhuman primates showed similar evidence of mirror self-recognition. Chimpanzees (Pan troglodytes) and orangutans (Pongo pygmaeus) pass the mirror self-recognition test with limited mirror training or exposure. Other species of primates, such as gorillas and monkeys, have not passed the mirror test, despite extensive mirror exposure and training (Gallup, 1979). This project examined a gorilla (G. gorilla gorilla) named Otto in a mark test. Using the modified mark-test we found more incidents of touching the marked area while Otto was in front of the mirror than when he was not in front of the mirror. These results indicate that Otto was able to show some evidence of self-awareness. 


\section{CHAPTER II}

\section{LITERATURE REVIEW}

Self-recognition has been extensively studied in infants and young children (Courage \& Howe, 2002; Amsterdam, 1972). This ability is assessed by observing the infant's behavior in the presence of mirrors and by performance on a mark test. In the mark test, the infant is marked unobtrusively with rouge (Asendorf, Warkentin, \& Baudonniere, 1996), paint (Courage, Edison, \& Howe, 2004), or a post-it-note (Rochat, 2003) on the child's head and face, so that the child is unable to detect the mark by nonvisual cues. An observer watches to see if the infant or young child moves to touch the mark while the child looks in the mirror. If the child reaches for the image in the mirror, it is thought that the child does not possess an understanding of self and sees the reflection as another individual. If, however, the child reaches for the mark on the child's own face, it is concluded that the child possesses some knowledge of self as revealed by recognizing the image in the mirror as being associated with the self.

The ability to recognize one's self in the mirror emerges at around eighteen months of age (Rochat, 2003), and self-reflection contingencies appear to emerge as early as 8 months of age (Courage, et al, 2004). According to Asendorpf et al. (1996), recognition of the self is one of the first important elements of early cognitive development. Mirror self-recognition (MSR) emerges as other cognitive changes are occurring, such as "language, symbolic play, deferred imitation, object permanence, empathy, altruism, [and] self-evaluation," enabling the young child to integrate information from multiple sources and construct an understanding of the outside world (Courage et al., p. 510). 
Rochat (2003) argued that before infants can identify themselves in the mirror they must first pass through the lower levels of self-awareness. At first infants are not aware that the mirror image is a reflection of self; rather, it is seen as an extension of the individual's environment. To move from this level, the infants must learn through experience to differentiate self from the environment and have experienced contingencies. After the infants are competent at differentiating self from the environment and learning contingencies, they will be able to identify themselves in the mirror and be able to pass a mark test.

Mirror self-recognition is used in nonhuman primate species as an indicator of emerging self-knowledge. Comparing infant self-recognition capabilities to those of nonhuman primates may indicate that similar cognitive capabilities and structures are present in all those who share the same these capabilities. These levels of self-awareness described by Rochat (2003) can be seen in non-human primates as well. According to a review by Gallup (1979), macaques, spider monkeys, baboons, and gibbons (see also Ujhelyi, Merker, Buk, \& Geissmann, 2000; Hyatt, 1998) treat their reflected image as an extension of their environment. Gallup (1970) found that when first presented with a mirror, chimpanzees treat the reflected image as a conspecific, i.e. an extension of their environment. After the chimpanzees become more familiar with the mirrored image, they began testing contingencies. Only after passing through these levels were chimpanzees able to pass the mark test.

Monkeys are able to differentiate self from the environment and use mirrors to solve problems through experience and training (Anderson, 1986; Brown, McDowell \& Lobinson, 1965; Itakura, 1987). Apes can also use mirrors to solve problems and guide 
behaviors (Nicholson \& Gould, 1995). These results indicate that anthropoid primates have the ability to learn contingencies and differentiate self from the environment. However, only the great apes, (chimpanzees, bonobos, and orangutans) have shown evidence of passing the mark test, indicating the highest level of self-awareness (Gallup, 1970, 1979; Lethmate \& Dücker, 1973; Suarez \& Gallup, 1981).

Gallup (1970) devised a method to examine self-recognition in nonhuman primates by modifying the classic mark test previously utilized with infants. After interacting with a mirror, the animal is anesthetized and marked on the face. When the animal recovers from the anesthesia the mirror is reintroduced and mark-directed behaviors are recorded. Gallup found that, initially, chimpanzees show social behaviors (e.g. treating the mirror as a conspecific) towards the mirror. After the social behaviors cease, self-directed behaviors (looking at self, staring at face, manipulating the mouth, etc.) begin. Chimpanzees who showed evidence of using mirrors to direct their behaviors were anaesthetized and marked with dye or paint on the eyebrow ridge. After recovering from the anesthesia, self-recognition was measured by the number of touches to the marked area. Using this procedure, Gallup argued that given sufficient exposure to mirrors, chimpanzees were able to pass the mark test and that this was evidence of selfrecognition.

Since that initial research, there have been numerous studies that have likewise indicated self-recognition in chimpanzees (Lin, Bard, \& Anderson, 1992; Gallup \& Povinelli, 1993), and orangutans (Lethmate \& Ducker, 1973; Suarez \& Gallup, 1981). The results for gorillas are not as decisive, with only two gorillas showing evidence of self-directed behaviors in the presence of mirrors (Koko and King, Patterson \& Cohn, 
1994; Swartz \& Evans, 1994). These two gorillas were living in an enriched environment with extensive human contact. These enriched conditions may have provided the necessary experiences that would lead to a positive response on a MSR task. Both Koko and King seemingly passed the mark test, but the data did not go through peer review nor were the experiments performed with experimentally blind experimenters. Current research, therefore, is ambiguous in indicating if gorillas are able to pass the mark test. Povinelli and Cant (1995) suggest that one reason there has been failure to find evidence of self-recognition in gorillas is that the cognitive processes responsible for selfconcept were changed by evolutionary adaptation so that they are not normally exhibited in the general population. Povinelli and Cant contend that the foundations of self-concept were developed to ensure survival in an arboreal lifestyle. The authors propose that the cognitive processes responsible for self-concept may have been sacrificed and modified when rapid physical growth was accepted to adapt with an increasingly terrestrial lifestyle. Changes in ontogeny can have a significant impact on selection pressures and the eventual evolution of the species, hence developmental mechanisms, genetic, and environmental influences produce phenotypic variation that selection might then act upon (Bjorkland, 2006).

According to the enculturation hypothesis (Call \& Tomasello, 1996) being reared in a species-atypical environment can lead to changes in that species' cognitive abilities (Bering, 2004; Bjorkland, 2006; Suddendorf \& Whiten, 2001; Tomasello et al, 1993). Probabilistic epigenesis predicts that there is flexibility in what cognitive structures have the potential to become. Great apes have large brains, and great flexibility in the formation of cognitive processes. In the great apes the enculturation hypothesis suggests 
that being raised in an enriched, human-like, environment will change the ape's cognition to resemble more closely the cognition of humans (Bering, 2001; Call \& Tomaselllo, 1996; Povinelli, Bering, \& Giambrone, 2001; Suddendorf \& Whiten, 2001). This may occur because the caretakers treat the captive raised apes as intentional agents, which influences their social cognition.

A second issue limiting the findings of self-recognition in gorillas may be aversion to eye-to-eye gazing. Gorillas consider direct eye contact a threat, which leads them to avoid eye-to-eye gazing (Shillito, Gallup, and Beck, 1999). They argue further that when in the presence of mirrors, gorillas may avoid eye contact and therefore not gain enough experience with their reflection to recognize themselves during a mark test. To address this issue, angled mirrors have been used to reduce direct eye contact. Changing the position of the mirrors did not increase positive results (Roeder, 1989; Shillito et al, 1999).

Nicholson and Gould (1995) addressed this issue by including training for a mirror-mediated object discrimination task before administering the MSR task. The authors hypothesized that the additional training to locate objects only visible by using a mirror would allow the gorilla sufficient opportunity to overcome the gaze aversion and learn mirror contingencies. It was also supposed that this training would increase selfdirected responses during post-training sessions. Nicholson and Gould found that a gorilla (Muke) was able to demonstrate mirror-mediated object discrimination. This task trained the gorilla to correctly identify the location of objects using mirror reflections. This training facilitated an increase in self-directed behaviors in the presence of a mirror. The authors argue that these behaviors were similar to the self-recognition behaviors 
found by Gallup. Although this study showed evidence that after specific training, gorillas are capable of recognizing themselves in the mirror, the question as to the ability of untrained gorillas to engage in self-directed behavior and to pass the mark test is still unsettled.

This proposed research seeks to answer the question as to whether or not gorillas can demonstrate self-directed behavior and pass the mark test in the presence of a mirror without specific mirror training. A positive mark test result would indicate that the gorilla recognizes himself in the mirror. One purpose of this research is to determine if sufficient exposure to a mirror will facilitate a gorilla's ability to successfully pass a mark test. Using a modified version of Gallup's mark test and a behavioral checklist derived from Lin et al (1992), this experiment seeks to find multiple evidence of self-recognition, first through self-directed and contingent behaviors, and then by a positive mark test result in a lowland gorilla named Otto. Given that Otto (Gorilla gorilla gorilla) was raised in an enriched environment, it is predicted that he will show a positive result on the mark test, as did the other two enriched gorillas. 


\section{CHAPTER III}

\section{METHODOLOGY}

\section{Subject}

Otto was approximately 45 years old at the time of testing. He is a male lowland gorilla (G. gorilla gorilla). Otto was brought to the Suncoast Primate Sanctuary in Palm Harbor, Florida, at approximately age 2, with various health problems including tuberculosis and septic arthritis. After recovering from his illnesses Otto was housed individually at the Sanctuary and has been housed in an enriched environment since that time. Otto has daily contact with various caregivers and is provided with many enrichment opportunities, such as foraging, watching television, painting, and playing with hula-hoops. This gorilla has not previously participated in research of any kind, nor has he had extended exposure to mirrors; however, he has had extended human interaction and social contact.

Otto's enclosure includes two main areas, an indoor area (his bedroom) and an outdoor area. The bedroom has a bench near one of the sides. Otto spends much of his time here relaxing, so this sight was chosen for placement of the mirror. Otto had full access to both areas of his enclosure during the entire experiment.

\section{Materials}

A Canon ZR100 was used to film all sessions. The sessions were recorded onto DVD's and sent to the university for coding. Observers KN, CB, and JM, (all FIU undergraduates) were blind to the hypothesis and coded the behaviors. During mirror trials, a large mirror was placed approximately 3 feet from the enclosure. Odorless, tasteless, transparent mineral oil (approximately the same consistency of the paint used in 
test) was used during the sham trials. A non-toxic, odorless, white paint (Plaid Washable Paint for Kids) was used for marking during the mark test. Otto's familiar trainer, DC, performed the application of the sham and painted marks. The experimenter, MA, trained the above coders according to a behavioral checklist, filmed all sessions, and performed all other procedures. After the set up of each trial, the experimenter started the video camera and left the area. The experimenter remained out of Otto's sight for the duration of trial, insured that no other individuals interacted with Otto, and only returned when the trial was over.

\section{Procedure}

A modification of Gallup's (1970) mark test procedure was used. It differed from the standard procedure in that Otto was not anesthetized because of its potential health risks. Otto progressed through four trial types: baseline, mirror exposure, sham, and test (see appendix 1). The initial behavioral baseline was recorded by video in ten 1-hour sessions without the presence of the mirror. These taped sessions occurred in the same location as all other trials.

After the baseline behavior was recorded, the mirror was introduced in thirty 45minute sessions. At no time was Otto's attention drawn by the experimenter to look at the mirror. These sessions were uninterrupted time in front of a plain mirror with no specific training, in which Otto was free to examine the mirror or not. This is similar to the familiarization procedure used by Shillito, Gallup, and Beck (1999), and provided Otto with an adequate opportunity to become familiar with the function of a mirror.

After the mirror familiarization trials, the test trials began. The first five days of trials were sham trials to habituate Otto to the procedure. A familiar trainer, DC, 
performed the sham marking procedure prior to the start of the session by rubbing a large paintbrush, filled with the colorless and odorless mineral oil, along the left brow ridge. Behaviors were recorded for 30 minutes without the mirror followed by 30 minutes in the presence of the mirror, with the order of mirror and no mirror sessions being counterbalanced. Sham trials were necessary to ensure that Otto was attending to the mark and not to the novel situation of his trainer painting his brow (Anderson, 1983; Patterson \& Cohn, 1994).

After the sham trials, two paint test trials were conducted. (During the application of the paint in test trial one, insufficient paint was applied so a third test trial was added.) Each test trial included a session with the mirror and without the mirror. The trainer marked the brow ridge as in the sham trials, this time with an odorless paint. Behavior was recorded in thirty-minute sessions, first without the mirror and then followed by the presence of the mirror, with mirror and no mirror sessions being counterbalanced. A control trial was also conducted at the end of the experiment. The control trial followed the same procedure as the test trials, with the inclusion of an additional mark being made on Otto's arm.

\section{Behavioral Measurements}

The percentage of time spent in front of a mirror was recorded. To be considered in front of the mirror, Otto had to have at least one body part on the bench located in his bedroom. This area was directly in front of where the mirror was located. When Otto left the bench to go to the outdoor area or the back part of his bedroom his behaviors were no longer recorded and he was considered out of the area. The number of touches to the marked area in both the sham and paint trials was also recorded. Mirror self-recognition 
was determined if there were significantly more touches during the test trials to the marked area in the presence of the mirror than in the absence of the mirror.

A modification of Lin et al's (1992) behavioral checklist was also used to code behaviors (see appendix 2). The behaviors were divided into five categories: non-mirror behaviors, mirror-directed behaviors, contingent movements, mirror-guided behaviors, and self-recognition. Non-mirror behaviors included face-directed behaviors, which were acts towards the face excluding the marked area without looking in the mirror, and markdirected behaviors, which were acts towards the marked area without looking in the mirror. Mirror-directed behaviors included: reaching, attempts to make physical contact with mirror or supporting apparatus; searching, attempts to look around or behind the mirror from an oblique angle; playing, attempts to interact with the mirror in a sociable manner; affect display, any signs of fear or aggression towards the mirror; and looking, gazing at the mirror without moving contingently or acting in a self-directed manner. Contingent movements were comprised of body movements, movement of head or body while the gorilla visually followed movements in the mirror, and facial movements, following the movements of the face in the mirror. Mirror-guided behaviors included: object reach, use of images in the mirror to manipulate an object; body-directed, use of mirror images to direct action to the gorilla's own body; and face-directed, use of the mirror to direct action to own face exclusive of the mark. Self-recognition was measured by mark-directed behaviors, e.g. the use of the mirror to direct action to the marked spot.

Observers were first trained to code behaviors using a video of four randomly selected segments of baseline trials, with a Pearson $r$ of .90 . The observers then coded the remaining segments by watching the videotaped sessions and recording the number and 
duration of the behaviors on a behavioral checklist. Each trial was broken into 15-minute segments for coding purposes. Observers were randomly assigned to the segments that they coded, with the stipulation that they code at least one segment for each trial, and all observers coded all segments for the sham and test trials. Twenty-four percent of the segments had 2 observers, and $21 \%$ of the segments had 3 observers. In segments that had 2 or more observers, only those behaviors that were recorded by at least 2 observers were included in the data analysis. This criterion resulted in the exclusion of 1037 behaviors, $27 \%$ of the total number, (515 of which were 'looking') from further data analysis. Only 1 mark-directed behavior and 1 mirror-mark-directed behavior were excluded. Overall correlation between observer's responses across all trials was $r=.60$. For mark-directed and mirror-mark-directed behaviors the correlation was slightly higher than the overall correlation, with $r=.77$. 


\section{CHAPTER IV}

\section{RESULTS}

Inferential statistics were used to calculate significant differences between behaviors in the various trial types. All t-values presented here reached a significance level of $p<.05$ unless indicated otherwise.

Non-Mirror Behaviors

During baseline trials, in which there was no mirror present, the percentage of the total time spent in non-mirror directed behaviors was distributed as follows: body directed (45\%), object directed (50\%), face directed (5\%). There were, on average, 32.9 object-directed behaviors per baseline trial, with an average of 33.7 seconds per behavior; 20.4 body directed behaviors, with an average of 49.02 seconds per behavior; and 7.7 face directed behaviors, with an average of 13.3 seconds per behavior.

Mirror exposure and test trials saw no difference from baseline in all non-mirror directed behaviors. Only the object directed behaviors in the mirror-sham trials showed a significant increase, $t(43)=2.13$, from baseline behaviors. There were, on average, more object directed behaviors in the sham trials than the mirror exposure trials, $t(69.9)=2.68$. When the sham trials were broken down into mirror and no mirror trials this effect only remaied significant for the mirror-sham trials, $t(47.3)=2.13$. There were more object directed behaviors in the sham trials than in the test trials, $t(15.9)=2.38$. There were more object directed behaviors in the mirror-sham trials than in the mirror-test trials, $t(8)$ $=2.96$. More face directed behaviors occurred in the mirror exposure trials than in the mirror-sham trials, $t(44.5)=3.76$. There were more face directed behaviors in the nomirror-test trials than the no-mirror-sham trials, $t(1)=1.28$. 


\section{Mirror-Directed Behaviors}

There were no mirror-directed behaviors recorded during the baseline trials. The percentage of the total time spent in mirror-directed behaviors during the mirror exposure trials was distributed as follows: reaching $(0 \%)$, searching $(5 \%)$, playing $(.1 \%)$, affect display (.1\%), and looking (95\%). Because reaching, searching, playing, and affect display comprised such a low percentage of the total behaviors they were excluded from further analyses. There were 19.2 looking average looking behaviors per trial, with an average duration of 6.17 seconds per trial.

There were no significant differences in the amount of looking behaviors across all trial types.

\section{Contingent and Mirror-Guided Behaviors}

Surprisingly, there was very little contingent or mirror-guided behavior observed. Only 14 contingent face movements, 2 contingent body movements, and 1 incident of mirror-guided face directed behavior were observed during 30 mirror exposure trials. Lin et al (1992) argue that developmentally, contingent behaviors must occur before selfrecognition can be achieved. This may not hold true for gorillas, as there was no evidence of contingent behaviors, yet Otto clearly passed the mark test (see next section).

\section{Mark-Directed Behaviors}

During the mirror-present sessions of the test trials Otto engaged in 16 mirrormark-directed behaviors (touching the marked area of his brow), with an average of 1.4 sec/touch. In both the mirror-present and mirror-absent sessions of the sham trials there were no mirror-mark-directed behaviors recorded. There were 10 mark directed behaviors during the mirror-absent sessions of the test trials. Although close inspection, 
by the experimenter, indicated that Otto found the mark accidentally, when he touched a water bottle to his face and inadvertently transferred the paint from his brow to the bottle. All 10 touches occurred following this incident. A chi-square comparing the mirror and no mirror session of the test and sham trials with 16 touches in the mirror-present test trial, 10 touches in the mirror-absent test trial, 0 touches in the mirror-present sham trial, and 0 touches in the mirror-absent sham trial resulted in significant differences, $\chi 2(3$, $\mathrm{N}=16$ ) $=28.05$. Comparing the number of touches during the mirror-present sessions of the test trials (16) and the number of touches during the mirror-absent sessions of the test trials $(10)$ yields a chi square of $\chi 2(2, \mathrm{~N}=16)=1.38$, which did not reach significance. However, this analysis may be misleading, as it is likely that some of Otto's response in the mirror-absent test condition was mediated by an accidental rubbing of the paint with his water bottle. Inspection of the videotape indicated far less precise touching of the marked area in the mirror-absent condition than in the mirror-present condition. In the mirror-absent trial the touches over shot the mark and were not in the center of the mark, rather they were on the edges and just slightly above the mark, and after all touching behavior ceased there was still a majority of the paint left. In the mirror-present trial, touches were more often in the center of the mark, more of the paint was disturbed and not much was left after Otto had completed inspection of the marked area. Thus, after including the qualitative differences among touching behaviors, it was concluded that Otto passed the mark test. 


\section{CHAPTER V}

\section{DISCUSSION}

Otto showed evidence of touching the marked area during the mirror-present test condition and not during the sham test trials. The number of touches to the marked area has generally been accepted as a sufficient indication of self-recognition (Asendorpf et al, 1996; Gallup, 1970, 1979; Lethmate \& Dücker, 1973; Rochat, 2003; Suarez \& Gallup, 1981) and as the key test for determining if an organism is capable of possessing a sense of awareness. Thus, we conclude that Otto passed the mark test and exhibited recognition of self.

We had hoped to see evidence of contingent movements and mirror-guided behaviors as further evidence of self-recognition. Lin et al (1992) found evidence that self-directed and contingent behaviors precede self-recognition in chimpanzees and we predicted that the same would be true in Otto's case. We found some evidence of selfdirected behaviors, but those behaviors were not mirror-guided and the frequency of contingent behaviors was very small. Our data indicate that mirror-guided and contingent behaviors may not be good indices of self-recognition in gorillas. De Veer and Van den Bos (1999) argue that evidence of mirror-guided self-directed behaviors and response to the mark test are both conditions that measure the same phenomenon. Thus, Otto failed to show significant evidence of mirror-guided behaviors but still possessed a sense of selfawareness as is evidenced by his performance on the mark test.

Gorillas' performance on the self-recognition test has not been consistent. Otto was more likely to touch the marked area when he was in front of the mirror than when he was not. There are arguments that those gorillas receiving extensive enrichment may 
have shown some evidence of self-recognition (Koko and King, Patterson \& Cohn, 1994;

Swartz \& Evans, 1994). It may be that these enriched gorillas were given experiences that enhanced their social cognition, enabling self-recognition to be expressed (Bering, 2004; Bjorkland, 2006; Tomasello, 2000). The results of this study suggest that latent social cognitive abilities exist in gorillas, however enriched upbringings may be necessary for these abilities to be exhibited.

Gallup argued that, "mirror self-recognition is impossible without a primitive form of the capacity to become the object of one's attention, to reflect on one's own existence, or to 'interview oneself"' (Povinelli, 1994, p. 573). Self-awareness and selfrecognition require the linking of a mirror image, which is a reflection of perceived reality, to the cognitions it represents, an abstract conception (Asendorpf et al, 1996). Positive responses on this MSR task by Otto indicate that gorillas are capable of conceptualizing about themselves in an abstract way, similar to the conceptualization processes evident in human infants. Evidence of self-recognition in gorillas may indicate the possibility of further shared cognitive processes between humans and apes. 


\section{List of References}

Amsterdam, B., (1972). Mirror self-image reactions before age two. Developmental Psychobiology, 5, 297-305.

Anderson, J. R., (1983). Responses to mirror-stimulation and assessment of selfrecognition in mirror-and peer-related stumptailed macaques. Quarterly Journal of Experimental Psychology, 35, 201-212.

Anderson, J. R., (1986). Mirror-mediated finding of hidden food by monkeys (Macaca tonkeana and Macaca fascicularis). Journal of Comparative Psychology, 100, 237-242.

Asendorpf, J. B., Warkentin, V., and Baudonniere, P. -M., (1996). Self-Awareness and other-awareness II: Mirror self-recognition, social contingency awareness, and synchronic imitation. Developmental Psychology, 32 (2), 313-321.

Bering, J. M. (2001). Theistic percepts in other species: Can chimpanzees represent the minds of non-natural agents? Journal of Cognition and Culture, 1, 107-137.

Bering, J. M. (2004). A critical review of the "enculturation hypothesis": the effects of human rearing on great ape social cognition. Animal Cognition, 7, 201-212.

Bjorkland, D. F. (2006). Mother knows best: Epigenetic inheritances, maternal effects, and the evolution of human intelligence. Developmental Review, 26, 213-242.

Boysen, S. T., and Berntson, G. G., (1989). Numerical competence in a chimpanzee (Pan troglodytes). Journal of Comparative Psychology, 103, 23-31.

Brown, W. L., McDowell, A. A., Lobinson, E. M., (1965). Discrimination of mirrored cues by rhesus monkeys. Journal of Genetic Psychology, 106, 123-128.

Call, J., Tomasello, M. (1996). The effects of humans on the cognitive development of apes. In: Russon, A. E., Bard, K. A., Parker, S. T. (Eds.), Reaching into Thought. Cambridge University Press, Cambridge, UK, pp. 371-403.

Courage, M. L., Edison, S. C., and Howe, M. L., (2004). Variability in the early development of visual self-recognition. Infant Behavior \& Development, 27, 509532.

Courage, M. L., and Howe, M. L., (2002). From infant to child: The dynamics of cognitive change in the second year of life. Psychological Bulletin, 128, 250-277. 
D'Amato, M. R., and Van Sant, P., (1988). The person concept in monkeys (Cebus apella). Journal of Experimental Psychology: Animal Behavior Processes, 14, 4355.

Gallup, G. G. Jr., (1970). Chimpanzees: Self-recognition. Science, 167, 86-87.

Gallup, G. G. Jr., (1979). Self-awareness in primates. American Scientist, 67, 417-421.

Gallup, G. G. Jr. and Povinelli, D. J., (1993). Mirror, mirror on the wall which is the most heuristic theory of them all? A response to Mitchell. New Ideas in Psychology, 11, 327-335.

Hyatt, C. W. (1998). Responses of gibbons (Hylobates lar) to their mirror images. American Journal of Primatology, 45, 307-311.

Itakura, S., (1987). Use of mirror to direct their responses in monkeys (Macaca fuscata fuscata). Primates, 28, 343-352.

Lethmate, J. and Dücker, G., (1973). Untersuchungen zum selbsterkennen im spiegel bei orang-utans und einigen anderen affenarten. [Studies on self-recognition in a mirror by orangutans and some other primate species]. Zeitschrift fur Tierpsychologie, 33, 248-269.

Lin, A. C., Bard, K. A., and Anderson, J. R., (1992). Development of self-recognition in chimpanzees (Pan troglodytes). Journal of Comparative Psychology, 106, 120127.

Menzel, C. R., (1999). Unprompted recall and reporting of hidden objects by a chimpanzee (Pan troglodytes) after extended delays. Journal of Comparative Psychology, 113, 426-434.

Nicholson, I. S., and Gould, J. E., (1995). Mirror mediated object discrimination and selfdirected behavior in a female gorilla. Primates, 36(4), 515-521.

Oden, D. L., Thompson, R. K., and Premack, D., (1990). Infant chimpanzee (Pan troglodytes) spontaneously perceive both concrete and abstract same/different relations. Child Development, 61, 621-631.

Patterson, F. G., and Cohn, R. H., (1994). Self-recognition and self-awareness in lowland gorillas. In: S. T. Parker, R. W. Mitchell, \& M. L. Boccia (Eds.), Self-awareness in Animals and Humans, (pp. 273-290). Cambridge: Cambridge University Press.

Povinelli, D. J., (1994). A theory of mind is in the head, not the heart. Behavioral and Brain Sciences, 17 (3), 573-574. 
Povinelli, D. J., Cant, J. G. H. (1995). Arboreal clambering and the evolution of selfconception. Quarterly Review of Biology, 70, 393-421.

Povinelli, D. J., Bering, J. M., and Giambrone, S. (2001). Toward a science of other minds: Escaping the argument by analogy. Cognitive Science. Special Issue: Primate Cognition, 24, 509-541.

Rochat, P., (2003). Five levels of self-awareness as they unfold early in life. Consciousness and Cognition, 12, 717-731.

Rumbaugh, D. M., and Steinmetz, G. T., (1971). Discrimination reversal skills of the lowland gorilla (Gorilla g. gorilla). Folia Primatologica, 144-152.

Schwartz, B. L., Hoffman, M. L., and Evans, S., (2005). Episodic-like memory in a gorilla: A review and new findings. Learning and Motivation, 36, 226-244.

Shillito, D. J., Gallup, G. G. Jr., and Beck, B. B., (1999). Factors affecting mirror behavior in western lowland gorillas, Gorilla gorilla. Animal Behavior, 57, 9991004 .

Suarez, S. D., and Gallup, G. G. Jr., (1981). Self-recognition in chimpanzees and orangutans, but not gorillas. Journal of Human Evolution, 10, 175-188.

Suddendorf, T., Whiten, A. (2001). Mental evolution and development: evidence for secondary representation in children, great apes, and other animals. Psychology Bulletin, 127, 629-650.

Swartz, K. B., and Evans, S., (1994). Social and cognitive factors in chimpanzee and gorilla mirror behavior and self-recognition. In S. T. Parker, R. W. Mitchell, and M. L. Boccia (Eds.), Self-awareness in Animals and Humans (pp. 189-206). Cambridge: Cambridge University Press.

Tomasello, M. (2000). Culture and cognitive development. Current directions in Psychological Science, 9, 37-40.

Tomasello, M., Savage-Rumbaugh, S., Kruger, A. C. (1993). Imitative learning actions on objects by children, chimpanzees, and enculturated chimpanzees. Journal of Child Development, 64, 1688-1705.

Ujhelyi, M., Merker, B., Buk, P., and Geissmann, T., (2000). Observations on the behavior of gibbons (Hylobates leucogenys, H. gabriellae, and H. lar) in the presence of mirrors. Journal of Comparative Psychology, 114, 253-262. 


\section{APPENDICES}


Appendix 1- Procedure Chart 
Procedure Chart

\begin{tabular}{|llrl|}
\hline Condition & Description & $\begin{array}{l}\text { Number } \\
\text { of Trials }\end{array}$ & $\begin{array}{l}\text { Duration } \\
\text { of Trial } \\
\text { minutes) }\end{array}$ \\
\hline 1. Baseline & no mirror & 10 & 60 \\
2. Mirror Exposure & mirror, no mark & 30 & 45 \\
3. Sham Trials & no mirror, false mark & 5 & 30 \\
4. Test Trials & mirror, false mark & 5 & 30 \\
& no mirror, paint mark & 3 & 30 \\
& mirror, paint mark & 3 & 30 \\
\hline
\end{tabular}

A description of the four trial types, including the number and duration of those trials. 
Appendix 2-Behavioral Checklist 


\begin{tabular}{|c|c|c|}
\hline \multicolumn{2}{|c|}{$\begin{array}{l}\text { Behavioral } \\
\text { Categories }\end{array}$} & Examples \\
\hline 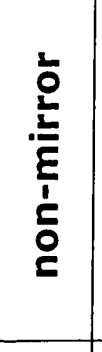 & $\begin{array}{l}\text { body directed } \\
\text { object directed } \\
\text { face directed } \\
\text { mark directed }\end{array}$ & $\begin{array}{l}\text { acts towards the body without looking in the mirror } \\
\text { acts towards an object without looking in the mirror } \\
\text { acts towards the face excluding the marked area } \\
\text { without looking in the mirror } \\
\text { acts towards the marked area without looking in the } \\
\text { mirror }\end{array}$ \\
\hline 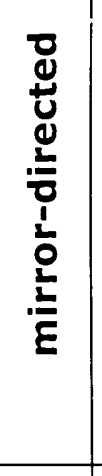 & $\begin{array}{l}\text { reaching } \\
\text { searching } \\
\text { playing } \\
\text { affect display } \\
\text { looking }\end{array}$ & $\begin{array}{l}\text { attempts to make physical contact with mirror or } \\
\text { supporting apparatus } \\
\text { attempts to look around or behind the mirror from } \\
\text { oblique angle } \\
\text { attempts to interact with the mirror in a sociable } \\
\text { manner } \\
\text { any signs of fear or aggression towards the mirror } \\
\text { gazing at the mirror without moving contingently or } \\
\text { acting in a self-directed manner }\end{array}$ \\
\hline 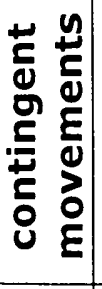 & $\begin{array}{l}\text { body } \\
\text { movements } \\
\text { facial } \\
\text { movements }\end{array}$ & $\begin{array}{l}\text { movement of head or body while gorilla visually } \\
\text { follows movements in the mirror } \\
\text { following the movements of the face in the mirror }\end{array}$ \\
\hline 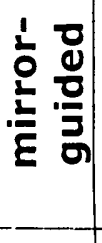 & $\begin{array}{l}\text { object reach } \\
\text { face directed }\end{array}$ & $\begin{array}{l}\text { use of images in the mirror to manipulate an object } \\
\text { use of the mirror to direct action to own face } \\
\text { exclusive of the mark }\end{array}$ \\
\hline 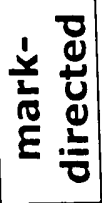 & mark directed & use of the mirror to direct action to the marked spot \\
\hline
\end{tabular}

Modified behavioral checklist, originally in Lin et al (1992). 